\title{
A novel electrochemical aptasensor based on layer-by-layer assembly of DNA-Au@Ag conjugates for rapid detection of aflatoxin $\mathbf{M}_{1}$ in milk samples
}

\author{
Yuanyuan Hui, ${ }^{1}$ Haishuai Peng, ${ }^{1}$ Fuxin Zhang, ${ }^{1}$ Lei Zhang, ${ }^{2}$ Liu Yufang, ${ }^{1}$ Aiqing Zhao, ${ }^{1}$ Rong Jia, ${ }^{1}$ \\ Bini Wang, ${ }^{1,3 *}$ and Yuxuan Song ${ }^{2 *}$ \\ ${ }^{1}$ College of Food Engineering and Nutritional Science, Shaanxi Normal University, Xi'an, Shaanxi 710119, China \\ ${ }^{2}$ College of Animal Science and Technology, Northwest A\&F University, Yangling 712100, China \\ ${ }^{3}$ Shaanxi Provincial Key Laboratory of Electroanalytical Chemistry, Northwest University, Xi'an, Shaanxi 710069, China
}

\section{ABSTRACT}

Aflatoxin $\mathrm{M}_{1}\left(\mathrm{AFM}_{1}\right)$ is a common toxin in dairy products that causes acute and chronic human health disorders. Thus, the development of a rapid and accurate $\mathrm{AFM}_{1}$ detection method is of vital importance for food safety monitoring. This work was to develop a novel electrochemical aptasensor for sensitive and specific determination of $\mathrm{AFM}_{1}$. The dendritic-like nanostructure was formed on the gold electrode surface by layer-by-layer assembly of gold-silver core-shell nanoparticles modified with DNA conjugates. In the presence of $\mathrm{AFM}_{1}$, the specific recognition between $\mathrm{AFM}_{1}$ and Apt caused the disassociation of the DNA controlled dual Au@Ag conjugates from the surface of the electrode, causing less methylene blue to bind to the surface and weakening the electrochemical signal. The more $\mathrm{AFM}_{1}$ there is, the weaker the electrochemical signal. Transmission electron microscope results showed that the successfully synthesized $\mathrm{Au} @ \mathrm{Ag}$ nanoparticles exhibited a core-shell structure with $\mathrm{Au}$ as core and $\mathrm{Ag}$ as shell, and their average diameter was about $30 \mathrm{~nm}$. Under optimal conditions, the electrochemical aptasensor showed a wide detection ranging from $0.05 \mathrm{ng} \mathrm{mL} \mathrm{m}^{-1}$ to $200 \mathrm{ng} \mathrm{mL}^{-1}$, and a low detection limit of $0.02 \mathrm{ng} \mathrm{mL} \mathrm{m}^{-1}$. Moreover, the proposed strategy has been successfully applied to the detection of $\mathrm{AFM}_{1}$ in cow, goat, and sheep milk samples with satisfactory recoveries ranging from $91.10 \%$ to $104.05 \%$. This work can provide a novel rapid detection method for $\mathrm{AFM}_{1}$, and also provide a new sensing platform for the detection of other toxins.

Key words: electrochemical biosensor, aptamers, Au@ $\mathrm{Ag}$ nanoparticles, aflatoxin $\mathrm{M}_{1}$

Received June 28, 2021

Accepted November 12, 2021.

*Corresponding authors: biniwang@snnu.edu.cn and syx98728@163 .com

\section{INTRODUCTION}

Aflatoxins (AF), a group of toxins structurally related to secondary metabolites, are produced by $A s$ pergillus flavus, Aspergillus parasiticus, and Aspergillus nomius (Sevim et al., 2019). The most common AF are aflatoxins $\mathrm{B}_{1}, \mathrm{~B}_{2}, \mathrm{G}_{1}, \mathrm{G}_{2}, \mathrm{M}_{1}$ and $\mathrm{M}_{2}$. Among them, aflatoxin $\mathrm{B}_{1}\left(\mathrm{AFB}_{1}\right)$ has the highest toxicity and strongest carcinogenicity (Feng et al., 2020), and was classified as a group 1 carcinogen by the International Agency for Research on Cancer in 1993 (Jalalian et al., 2018; Zhao et al., 2021). Aflatoxin $\mathrm{M}_{1}\left(\mathrm{AFM}_{1}\right)$, a major hydroxylated metabolite of $\mathrm{AFB}_{1}$ in the liver (Khodadadi et al., 2018; Fang et al., 2020), is frequently detected in milk of mammals that have ingested $\mathrm{AFB}_{1}$ contaminated feed so that it is also called "milk toxin" (Zhou et al., 2019; Hamami et al., 2021). During the process of milk pasteurization or other thermal treatments, there is little possibility of inactivation of $\mathrm{AFM}_{1}$ in milk. Even at a low level of concentration, $\mathrm{AFM}_{1}$ could cause an enormous and serious threat such as hepatotoxic, neurotoxic, and even immunosuppressive effects to human health (Wang et al., 2016; Gratz et al., 2020). Considering that humans, particularly infants and children, have a great need for dairy products, many countries and regions have implemented regulations to control the content of $\mathrm{AFM}_{1}$ in dairy products. Both the United States and China set a maximum residue limit in milk at $0.5 \mu \mathrm{g} \mathrm{kg}^{-1}$, whereas the European Union set a lower permitted level of $0.05 \mu \mathrm{g} \mathrm{kg}^{-1}$ in milk (European Commission, 2010; Food and Drug Administration 2015; Ministry of Agriculture of China, 2017). Consequently, it is necessary for $\mathrm{AFM}_{1}$ in milk or dairy products to be monitored and detected.

Common methods for $\mathrm{AFM}_{1}$ detection mainly include HPLC (Sereshti et al., 2019), liquid chromatographymass spectrometry (LC-MS; Cavaliere et al., 2007), and ELISA (Jiang et al., 2013). Both HPLC and LCMS are the most frequently used techniques because of their high accuracy and sensitivity, but the main drawback is that they require expensive equipment, 
multiplex pretreatment, and professional operators. Although ELISA is rapid and simple, it may produce both false positive and false-negative results for toxin trace detection. These disadvantages limit their application in real-time and rapid detection of toxins (Jalalian et al., 2021).

Aptamers (Apts) are single-stranded DNA or RNA molecules that can bind to proteins, cells, metal ions and small molecules with high affinity and specificity (Ellington and Szostak, 1990; Tuerk et al., 1993). As a novel targeted recognition molecule, aptamers have another name, chemical antibodies. However, compared with antibodies, Apts still have some distinct advantages, such as low cost, excellent stability, convenient preservation, easy synthesis, and high affinity. Considering the advantages of aptamers, researchers have developed various aptamer-based sensors (aptasensors), including colorimetric aptasensors (Qiao et al., 2021; Zhang et al., 2021), surface plasmon resonance aptasensors (Kotlarek et al., 2020), surface-enhanced Raman spectroscopy aptasensors (He et al., 2020), fluorescence aptasensors (Bi et al., 2021; Shi et al., 2021) and electrochemical aptasensors (Jalalian et al., 2018). Owing to the simple operation, rapid detection and high sensitivity and selectivity, electrochemical aptasensors have been widely used in food analysis, clinical testing, environmental monitoring and life science. Nanomaterials with high conductivity are commonly used as signal amplifiers for electrochemical aptasensors, and gold nanoparticles (AuNP), a class of typical and representative nanomaterials, have been widely adopted to construct the electrochemical sensing interface. Chen et al. (2018) constructed 3 different electrochemical aptasensors (dual AuNP conjugate, single AuNP, conjugate and the traditional method) based on the specific recognition ability of aptamers and the superior physical and chemical properties of AuNP (Chen et al., 2018). Results found that the use of DNA controlled dual AuNP conjugate could greatly amplify the electrochemical signal and improve the sensing performance significantly compared with single AuNPs conjugate or without the involvement of AuNP. However, compared with AuNP, the gold-silver core-shell nanoparticles $(\mathbf{A u} @ \mathbf{A g})$ not only exhibit better conductivity because of the synergistic effects of individual nanomaterials ( $\mathrm{Xu}$ et al., 2015), but can also compensate for the deficiencies of individual nanomaterials and provide an excellent platform for the further immobilization of oligonucleotide (Amouzadeh Tabrizi et al., 2017; Song et al., 2018).

In this work, we developed a simple electrochemical aptasensor for highly sensitive and selective detection of $\mathrm{AFM}_{1}$. The Apts-Au@Ag and cDNA2-Au@Ag conjugates were assembled onto the electrode interface sequentially by specific base pairing, forming DNA controlled dual Au@Ag conjugates. The presence of $\mathrm{AFM}_{1}$ led to the dissociation of DNA controlled dual Au@ $\mathrm{Ag}$ conjugates from the electrode interface. Methylene blue (MB) was used as the electroactive substance and intercalated on the double-stranded DNA to produce the electrochemical signal. The larger the concentration of $\mathrm{AFM}_{1}$, the weaker the electrochemical signal. The developed electrochemical aptasensor provides a promising strategy for the rapid and accurate detection of $\mathrm{AFM}_{1}$.

\section{MATERIALS AND METHODS}

\section{Reagents and Materials}

All oligonucleotides (HPLC purified) used in this work were synthesized by Shanghai Biotechnology Co. Ltd., and the oligonucleotide sequences are as follows:

- cDNA1: 3'-ATGTGGAAACTATCTAGCAGT$\left(\mathrm{CH}_{2}\right)_{6}-\mathrm{SH}-5^{\prime}$

- $\mathrm{AFM}_{1}$ aptamers (Apt): 3'-ACTGCTAGAGATTTTCCACATTTCTGTGTGT- $\left(\mathrm{CH}_{2}\right)_{6}{ }^{-} \mathrm{SH}-5^{\prime}$. The underlined portion of sequence is aptamer, which was designed according to the literature (Jalalian et al., 2018).

- cDNA2: 3'-ACACACAGAAATGTGGAAACTATCTAGCAGTGTCTCGGTGT- $\left(\mathrm{CH}_{2}\right)_{6}{ }^{-} \mathrm{SH}-5^{\prime}$.

Oligonucleotides were dissolved in $20 \mathrm{~m} M$ Tris- $\mathrm{HCl}$ buffer ( $\mathrm{pH}$ 7.4) containing $140 \mathrm{~m} M \mathrm{NaCl}, 5 \mathrm{~m} M \mathrm{KCl}, 1 \mathrm{~m} M$ $\mathrm{MgCl}_{2}$, and $1 \mathrm{mMCaCl}$. Aflatoxin $\mathrm{M}_{1}$, aflatoxin $\mathrm{M}_{2}$, $\mathrm{AFB}_{1}$, aflatoxin $\mathrm{B}_{2}\left(\mathrm{AFB}_{2}\right)$, aflatoxin $\mathrm{G}_{1}\left(\mathrm{AFG}_{1}\right)$, aflatoxin $\mathrm{G}_{2}\left(\mathrm{AFG}_{2}\right)$, ochratoxin $\mathrm{A}(\mathbf{O T A})$, and fumonisin $\mathrm{B}_{1}\left(\mathbf{F B}_{1}\right)$ were purchased from Sigma-Aldrich. Hydrogen tetrachloroaurate trihydrate $\left(\mathrm{HAuCl}_{4} \cdot 3 \mathrm{H}_{2} \mathrm{O}\right)$, Tris (2-carboxyethyl) phosphine hydrochloride (TCEP), silver nitrate $\left(\mathrm{AgNO}_{3}\right)$, 6-mercaptohexanol (MCH), and $\mathrm{MB}$ were ordered from Aladdin Chemistry Co. Ltd. Other reagents were of analytical grade and used without further purification.

\section{Apparatus}

Electrochemical measurements including square wave voltammetry (SWV), cyclic voltammetry, electrochemical impedance spectroscopy (EIS), and differential pulse stripping voltammetry (DPV) were carried out on an electrochemical workstation (CH Instruments) with a 3-electrode system composed of a gold electrode as the working electrode, a platinum wire electrode as the counter electrode, and $\mathrm{Ag}$ or $\mathrm{AgCl}$ as the reference 
electrode. Transmission electron microscope (TEM) images were collected using a HT-7700 transmission electron microscope (Hitachi) with an accelerating voltage of $80 \mathrm{kV}$. The UV-visible absorption spectra were obtained using a UV300 spectrophotometer (InsMark).

\section{Preparation of DNA (Apts and cDNA2)- Au@Ag Conjugates}

The AuNP were synthesized by the classic Turkevich citrate reduction method (Frens, 1973). Briefly, $100 \mathrm{~mL}$ of $\mathrm{HAuCl}_{4}$ solution $(0.01 \%$, wt/vol) was heated to boiling, and then $1.5 \mathrm{~mL}$ of trisodium citrate $(1 \%$, wt/vol) was immediately added to the solution and mixed thoroughly. Then the mixture was heated until it changed to deep wine red. Thereafter, the obtained AuNPs solution was cooled to room temperature and then stored at $4^{\circ} \mathrm{C}$ in a brown glass bottle for further use.

The Apts-Au@Ag conjugates was synthesized according to previously reported methods with slight modifications (Amouzadeh Tabrizi et al., 2017; Yao et al., 2017). To activate sulfhydryl groups, $100 \mu \mathrm{L}$ of 10 $\mu M$ thiolated Apts was added to $100 \mathrm{~mL}$ of $10 \mathrm{mM}$ TCEP and the mixture was kept at room temperature for $2 \mathrm{~h}$. Subsequently, $3 \mathrm{~mL}$ of the AuNP solution was added to the mixture and stored at $4^{\circ} \mathrm{C}$ for $24 \mathrm{~h}$ to form the Apts-Au conjugates through $\mathrm{Au}-\mathrm{S}$ bond. The obtained conjugates were centrifuged at $5,600 \times g$ for 20 min at room temperature to remove unbound Apts, and then redispersed in distilled water. Afterward, 60 $\mu \mathrm{L}$ of ascorbic acid $(10 \mathrm{mM})$ and $100 \mu \mathrm{L}$ of $\mathrm{AgNO}_{3}$ solution $(0.01 \mathrm{~m} M)$ were added to the conjugates dropwise and gently stirred for 5 min to form Apts-Au@Ag conjugates. After centrifugation at 5,600 $\times g$ for $20 \mathrm{~min}$ at room temperature, the obtained Apts-Au@Ag conjugate sediments were dispersed in distilled water for further use. The preparation process of cDNA2-Au@ Ag conjugates was the same as that for Apts-Au@Ag conjugates except for the cDNA2.

\section{Fabrication of Electrochemical Aptasensor}

Figure 1 shows the construction process of the electrochemical aptasensor. The bare gold electrode (GE) was first polished with $0.05-\mu \mathrm{m}$ alumina powder and washed ultrasonically in ethanol and water (1:1) for 5 min. After that, GE was immersed in a freshly prepared piranha solution $\left(98 \% \mathrm{H}_{2} \mathrm{SO}_{4}: 30 \% \mathrm{H}_{2} \mathrm{O}_{2}=3: 1\right.$, vol/vol) for $10 \mathrm{~min}$, rinsed thoroughly with ultrapure water, and dried under a stream of nitrogen.

The cleaned GE was immersed in $20 \mu \mathrm{L}$ of SH-cDNA1 solution $(3.0 \mu M)$ for $4 \mathrm{~h}$ at room temperature, and then washed gently with Tris buffer solution. To block the nonspecific binding site, $10 \mu \mathrm{L} \mathrm{MCH}$ was dropped on the surface of cDNA1/GE (the slash indicates a combination or layering of the components). After drying, the cDNA1/GE was incubated in $30 \mu \mathrm{L}$ Apts-Au@ $\mathrm{Ag}$ conjugates for $1 \mathrm{~h}$ at room temperature to make Apts-Au@Ag conjugates bind to the cDNA1 by specific base pairing. Then, the Apts-Au@Ag/cDNA1/GE was immersed in $30 \mu \mathrm{L}$ of $\mathrm{cDNA} 2-\mathrm{Au} @ \mathrm{Ag}$ conjugates for $1 \mathrm{~h}$ at room temperature, and free Apts on the Apts$\mathrm{Au} @ \mathrm{Ag}$ conjugates were combined with cDNA2-Au@ $\mathrm{Ag}$ conjugates to form DNA controlled dual $\mathrm{Au} @ \mathrm{Ag}$ conjugates. The fabricated aptasensor was stored at $4^{\circ} \mathrm{C}$ for future use.

\section{Electrochemical Characterization}

To verify the successful fabrication of the electrochemical aptasensor, EIS, and SWV characterizations of bare GE, cDNA1/GE, Apt-Au@Ag/cDNA1/ GE, cDNA2-Au@Ag/Apt-Au@Ag/cDNA1/GE, and $\mathrm{AFM}_{1} / \mathrm{cDNA} 2-\mathrm{Au} @ \mathrm{Ag} / \mathrm{Apt}-\mathrm{Au} @ \mathrm{Ag} / \mathrm{cDNA} 1 / \mathrm{GE}$ were performed, respectively. The electrolyte solution used in electrochemical characterization was $5 \mathrm{mM}$ $\left[\mathrm{Fe}(\mathrm{CN})_{6}\right]^{3-/ 4-}$ solution containing $0.1 \mathrm{M} \mathrm{KCl}$, and $\left[\mathrm{Fe}(\mathrm{CN})_{6}\right]^{3-/ 4-}$ worked as the redox indicator. Electrochemical impedance spectroscopy was carried out at an initial potential of $0.1 \mathrm{~V}$, an amplitude of $0.005 \mathrm{~V}$ and a scanning range from 1 to $10^{5} \mathrm{~Hz}$. The SWV scanned from -0.3 to $0.4 \mathrm{~V}$ with an amplitude of $0.025 \mathrm{~V}$ and a frequency of $15 \mathrm{~Hz}$.

\section{Electrochemical Detection of AFM 1}

The determination of $\mathrm{AFM}_{1}$ was performed as follows: The fabricated aptasensor was incubated with 20 $\mu \mathrm{L}$ of different concentrations of $\mathrm{AFM}_{1}(0.05,0.1,1,10$, 50,100 , and $200 \mathrm{ng} \mathrm{mL}^{-1}$ ) for $45 \mathrm{~min}$ at room temperature. After thoroughly capturing, the aptasensor was carefully rinsed with PBS to remove specific conjugates of $\mathrm{AFM}_{1}$-Apts-Au@Ag/cDNA2-Au@Ag. Thereafter, the aptasensor was further incubated with $20 \mu \mathrm{L}$ of MB $(4 \mathrm{mM})$ for $40 \mathrm{~min}$ at room temperature, and the electrochemical signals were recorded using DPV. The DPV measurements were carried out in $0.1 M$ PBS (pH $=7.0$ ) containing $0.02 \mathrm{M} \mathrm{KCl}$ with a scan range of 0.1 to $0.3 \mathrm{~V}$, a pulse amplitude of $0.05 \mathrm{~V}$, and a pulse width of $0.05 \mathrm{~s}$.

\section{Milk Sample Preparation}

Cow, goat, and sheep milk samples were obtained from China Resources Vanguard supermarket (Shaanxi, China), the Redstar Meiling Dairy Co., Ltd. (Shaanxi, China), and the Gansu Yuansheng Agriculture and Animal Husbandry Technology Co., Ltd. (Gansu, China), 
respectively. They were treated according to the reported literature with minor modifications (Jiang et al., 2020). In brief, the milk samples $(25 \mathrm{~mL})$ were heated in a water bath $\left(65^{\circ} \mathrm{C}\right)$ for $30 \mathrm{~min}$ and centrifuged at $1,510 \times g$ for $20 \mathrm{~min}$ at room temperature. The upper fat layer was discarded, and the aqueous phase at the middle of the centrifugal tube was carefully recovered. The recovered liquid was spiked with various concentrations of $\mathrm{AFM}_{1}$. Afterward, $2 \mathrm{~mL}$ of recovered liquid was mixed with $6 \mathrm{~mL}$ of methanol (HPLC grade). The mixture was ultrasonically treated for $30 \mathrm{~min}$ before being filtered through a disposable syringe filter $(0.22$ $\mu \mathrm{m})$. Finally, for spiked recovery experiments, $0.2 \mathrm{~mL}$ of filtered supernatant was diluted 1,000 times with PBS and spiked with different concentrations of $\mathrm{AFM}_{1}$.

\section{RESULTS AND DISCUSSION}

\section{The Sensing Principle for Determination of AFM}

Figure 1A exhibits a schematic illustration of the synthesis of DNA-Au@Ag conjugates. First, the DNA
(Apt or cDNA2) modified with $\mathrm{SH}$ at the $5^{\prime}$ end was immobilized on the AuNPs surface via $\mathrm{Au}-\mathrm{S}$ bonds. Then the DNA-AuNP are encapsulated with silver. During this process, DNA might be embedded partly into the silver shell layer and lose the bio-recognition features. To avoid the problem, the base sequences of Apt (TTCTGTGTGT) and cDNA2 (GTCTCGGTGT) were used to protect the bio-recognition part.

Figure 1B illustrates the principle of the electrochemical aptasensor for determination of $\mathrm{AFM}_{1}$. The SHcDNA1 was immobilized on the surface of GE through $\mathrm{Au}-\mathrm{S}$ bond. Then cDNA1/GE was treated with $\mathrm{MCH}$. The MCH not only blocks the remaining active sites and avoids nonspecific adsorption, but also maintains the linear structure of cDNA1 and increases its hybridization efficiency. The Apts-Au@Ag and cDNA2-Au@ $\mathrm{Ag}$ conjugates could be attached to cDNA1/GE via specific base pairing, successively, eventually forming DNA controlled dual Au@Ag conjugates. When $\mathrm{AFM}_{1}$ was absent, $\mathrm{MB}$, as an electroactive substance, could intercalate into double-stranded DNA, binding specifically to guanine and producing a strong electrochemical
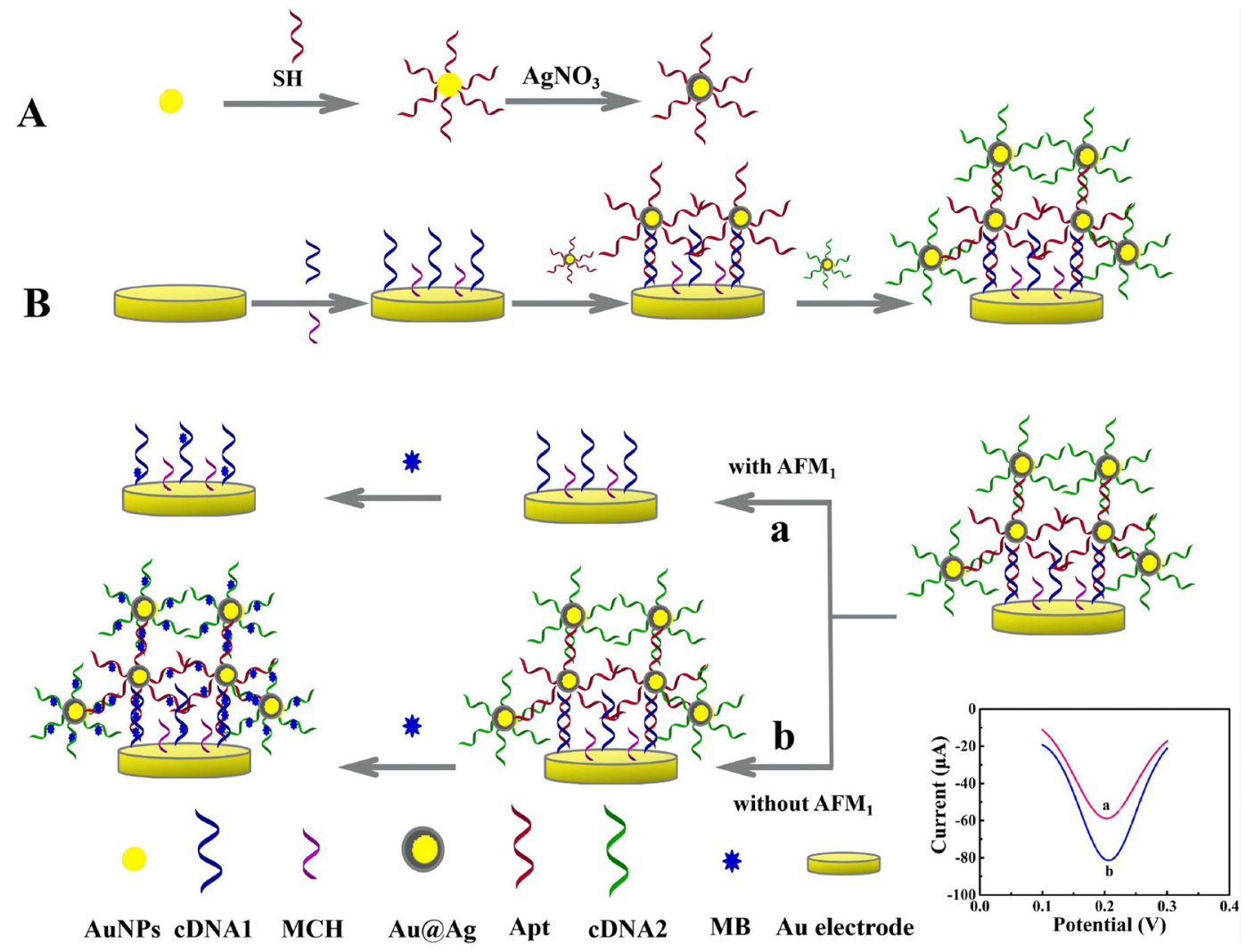

Figure 1. Schematic of the fabrication of the electrochemical aptasensor for the detection of aflatoxins in milk. (A) Illustration of the synthesis of DNA-Au@Ag conjugates; (B) illustration of the principle of the electrochemical aptasensor for determination of aflatoxin $\mathrm{M}_{1}\left(\mathrm{AFM}_{1}\right)$. $\mathrm{SH}=$ sulfhydryl group; AuNP = gold nanoparticles; $\mathrm{cDNA} 1$ and $\mathrm{cDNA} 2=$ oligonucleotide sequences; $\mathrm{MCH}=\mathrm{mercaptohexanol}$; Au@Ag = gold-silver core-shell nanoparticle; Apt = aptamer; $\mathrm{MB}=$ methylene blue. 
signal. But in the presence of $\mathrm{AFM}_{1}, \mathrm{AFM}_{1}$ preferentially bonded to Apt due to the high affinity between $\mathrm{AFM}_{1}$ and Apt, causing dissociation of DNA controlled dual $\mathrm{Au} @ \mathrm{Ag}$ conjugates from the surface of cDNA1/ GE, which in turn resulted in less accumulation of MB on the surface of GE and a decrease of electrochemical signals. There is an inverse proportional relationship between electrochemical signals and $\mathrm{AFM}_{1}$ concentrations, and the higher the $\mathrm{AFM}_{1}$ concentration, the weaker the electrochemical signal.

\section{Characterization of the Au@Ag Nanoparticles}

To confirm the successful syntheses of $\mathrm{Au} @ \mathrm{Ag}$ nanoparticles, the nanoparticles were characterized by TEM, high-angle annular dark field-scanning TEM-energy-dispersive X-ray spectrometry (HAADFSTEM-EDX), and UV-vis spectroscopy. The structural characterization of the synthesized Au@Ag nanoparticles was analyzed by TEM and images are shown in Figure 2A; it can be seen that nanoparticles, with a size of approximately $30 \mathrm{~nm}$, were relatively regular and possessed a core-shell nanostructure. The EDX spectrum of the $\mathrm{Au} @ \mathrm{Ag}$ nanoparticles demonstrated that the elements of $\mathrm{Au}$ and $\mathrm{Ag}$ were distributed homogeneously within the core-shell nanostructure (Figure $2 \mathrm{~B}$ and $2 \mathrm{C}$ ). The superimposed image of $\mathrm{Au} @ \mathrm{Ag}$ nanoparticles shows a clear boundary between the $\mathrm{Au}$ and $\mathrm{Ag}$ segments (Figure 2D), further confirming the $\mathrm{Au}$ Ag core-shell nanostructure. To further study the optical characterization of AuNPs, Au@Ag nanoparticles and DNA-Au@Ag conjugates, we analyzed their UV-vis spectra to confirm the successful formation of these nanocomposites. It can be seen from Figure 2E that AuNP illustrated a strong absorption peak in the UV region around $525 \mathrm{~nm}$ (curve a). When the Au@ $\mathrm{Ag}$ nanoparticles were formed by adding AgNP, the absorption peak of $\mathrm{Au}$ disappeared, and only the characteristic absorption peak of $\mathrm{Ag}$ was clearly observed at $420 \mathrm{~nm}$, suggesting that the Au@Ag core-shell structure was successfully formed with the AgNPs coating the outside (curve b). The UV-vis spectra confirmed that the synthesized $\mathrm{Au} @ \mathrm{Ag}$ nanoparticles had only one absorption band of $\mathrm{Ag}$ at $420 \mathrm{~nm}$, indicating that the $\mathrm{Au} @ \mathrm{Ag}$ core-shell structure was successfully formed with the AgNPs coating the outside. When thiolated DNA (Apts or cDNA2) was combined with AuNPs through Au-S bond, the addition of AgNPs resulted in the disappearance of the absorption peak of AuNP at $525 \mathrm{~nm}$, with 2 absorption peaks at $257 \mathrm{~nm}$ (DNA) and $420 \mathrm{~nm}$ (AgNP) observed (curve c). These results indicated that AuNP were completely covered by AgNP but DNA was not, which further proved that DNA-
$\mathrm{Au} @ \mathrm{Ag}$ conjugates were successfully formed with DNA extending outside for the binding of another DNA-Au@ Ag conjugate via specific base pairing.

To further explore the reasons for the disappearance of the absorption peak of $\mathrm{Au}$ after the formation of $\mathrm{Au} \mathrm{Ag}$ nanoparticles, the UV-vis absorption spectra of $\mathrm{Au} @ \mathrm{Ag}$ nanoparticles containing different amounts of silver nitrate was also characterized. As illustrated in Figure 2F, with the increasing amount of silver nitrate added, the absorption intensity of the mixture gradually increased, and the color gradually changed from wine red to yellow. Only when $50 \mu \mathrm{L}$ of $\mathrm{AgNO}_{3}$ was added did 2 absorption peaks of AuNP and AgNP appear simultaneously, and the absorption peaks of AuNP showed a blue shift compared with that of pure AuNP. The main reason might be that the encapsulation of $\mathrm{Ag}^{+}$changed the dielectric constant of the $\mathrm{Au}$ and scattering ability of light at different wavelengths. These obtained results were in accordance with the previously published results on $\mathrm{Au} @ \mathrm{Ag}$ nanoparticles (Mao et al., 2017; Zhao et al., 2018), which also further demonstrated the successful synthesis of $\mathrm{Au} @ \mathrm{Ag}$ nanoparticles.

\section{Electrochemical Characterization of Different Electrodes}

Electrochemical impedance spectroscopy was used to monitor the fabrication process of the electrochemical aptasensor. For EIS, the semicircle diameter can be used to evaluate the electron transfer resistance $\left(\boldsymbol{R}_{e t}\right)$ on the surface of the electrode using $\left[\mathrm{Fe}(\mathrm{CN})_{6}\right]^{3-/ 4-}$ as the redox probe, and the increase in semicircle diameter signifies the increase in the $R_{e t}$ value. As shown in Figure $3 \mathrm{~A}$, the $R_{e t}$ of the bare GE was relatively low (curve a). When the SH-cDNA1 was self-assembled onto the surface of the GE by Au-S bond, an obviously increased $R_{e t}$ value was observed (curve b). This is because the negatively charged phosphate backbone of cDNA1 hindered electron transfer, which also demonstrated that the cDNA1 was successfully immobilized on the electrode surface. After the successive immobilization of the Apts-Au@Ag (curve c) and the cDNA2-Au@ $\mathrm{Ag}$ conjugates (curve d) onto the GE, the $R_{e t}$ were significantly enhanced. This could be caused by the increase in negative charge density of the double-helical DNA structure. It was noticeable, however, that the $R_{\text {et }}$ value obviously decreased when incubating with $10 \mathrm{ng} \mathrm{mL}^{-1} \mathrm{AFM}_{1}$ (curve e). This suggested that the preferential binding of Apt toward $\mathrm{AFM}_{1}$ resulted in the disassociation of Apts-Au@Ag from the surface of the GE. Then the $R_{e t}$ value continued to reduce when the GE was immersed in $4 \mathrm{mM} \mathrm{MB}$ solution (curve $\mathrm{f}$ ). 

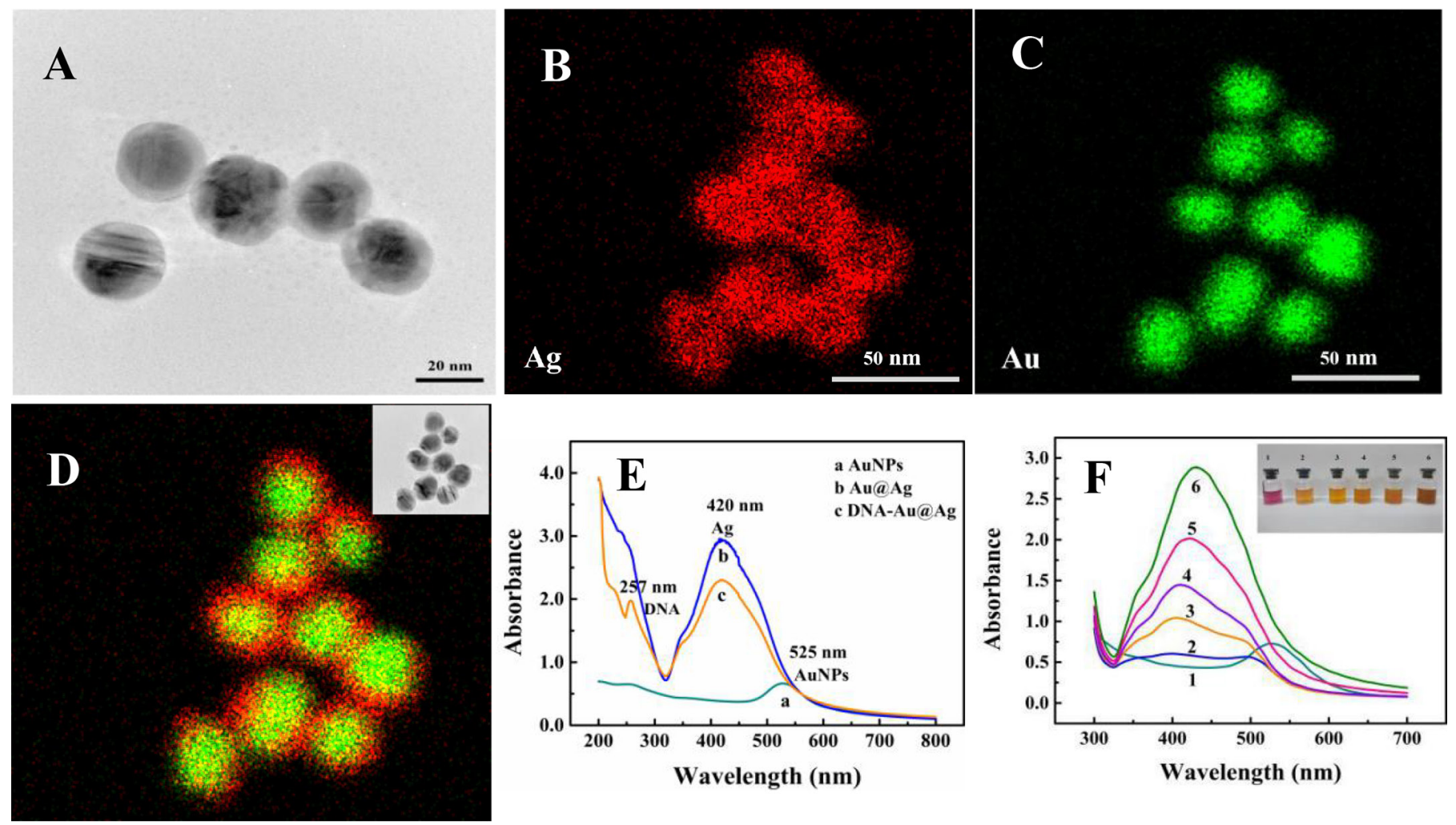

Figure 2. Transmission electron micrographs of (A) gold-silver core-shell nanoparticles (Au@Ag); high-angle annular dark field-scanning TEM-energy-dispersive X-ray spectrometry (HAADF-STEM-EDX) elemental mapping of (B) Ag, (C) Au, and superimposed image of (D) Au@ Ag; (E) UV-visible (Vis) spectra of AuNPs (a), Au@Ag (b), and DNA-Au@Ag (c); the amount of $\mathrm{AgNO}_{3}$ added was 350 $\mu \mathrm{L}$; and (F) UV-Vis spectra of $\mathrm{Au} @ \mathrm{Ag}$; the amount of $\mathrm{AgNO}_{3}$ added was (curves 1 to 6): 0, 50, 150, 250, 350, and $450 \mu \mathrm{L}$.

A

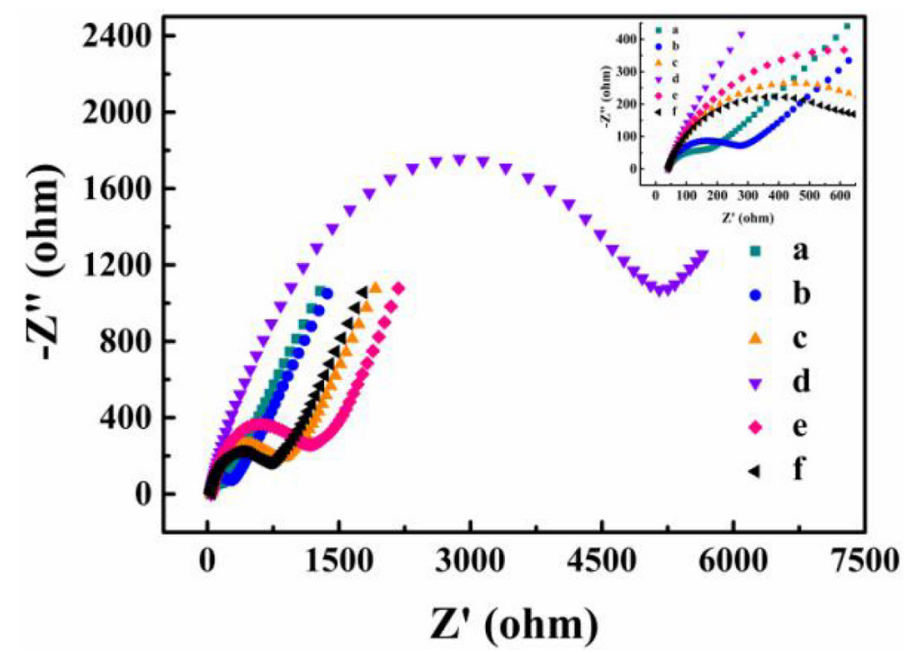

B

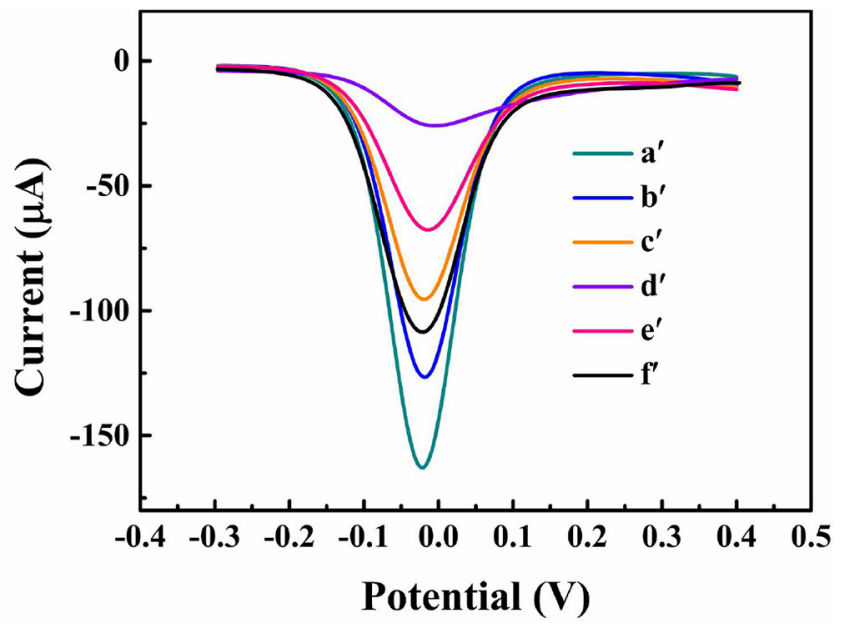

Figure 3. Electrochemical impedance spectroscopy (A) and square wave voltammetry (B) of different modification steps of the aptasensor in $5 \mathrm{mM}\left[\mathrm{Fe}(\mathrm{CN})_{6}\right]^{3-4-}$ containing $0.1 \mathrm{M} \mathrm{KCl}$ : (a, a') bare GE; (b, b') cDNA1/GE; (c, c') Apt-Au@Ag/cDNA1/GE; (d, d') cDNA2-Au@Ag/Apt -Au@Ag/cDNA1/GE; (e, e') AFM1/cDNA2-Au@Ag/Apt-Au@Ag/cDNA1/GE; and (f, f') MB/AFM1/cDNA2-Au@Ag/Apt-Au@Ag/cDNA1/ GE. $\mathrm{GE}=$ gold electrode; $\mathrm{cDNA} 1$ and cDNA2 = oligonucleotide sequences; Apt = aptamer; Au@Ag = gold-silver core-shell nanoparticle; MB $=$ methylene blue. Slashes indicate layers of the aptasensors. 
The reason could be attributed to the fact that $\mathrm{MB}$ is an electroactive substance that could intercalate into the double-stranded DNA, promoting the transfer of electrons. These results proved that the aptasensor was successfully fabricated.

The SWV measurements were also recorded to further prove the results of EIS. As shown in Figure 3B, the bare GE showed a strong current signal (curve $\mathrm{a}^{\prime}$ ). The current signal was reduced after the cDNA was assembled (curve b'). When Apts-Au@Ag and cDNA2$\mathrm{Au} \mathrm{Ag}$ conjugates were immobilized on the surface of electrode, a clearly declining current was observed (curve $\mathrm{c}^{\prime}$ and $\mathrm{d}^{\prime}$, respectively). However, the addition of $\mathrm{AFM}_{1}$ resulted in an increasing current (curve $\mathrm{e}^{\prime}$ ). Subsequently, the current signal was further enhanced when the electrode was immersed in MB solution (curve $\left.\mathrm{f}^{\prime}\right)$. These results were consistent with those obtained by EIS experiments above, indicating the feasibility of our scheme for $\mathrm{AFM}_{1}$ detection.

\section{Optimization of the Experimental Conditions}

To acquire the optimum analytical performance, several experiment parameters that could affect the electrochemical signal of aptasensor were optimized by the cyclic voltammetry method. The Au@Ag nanoparticles plays an important role in the construction of the electrochemical aptasensor. Thus, the effect of the addition amount of $\mathrm{AgNO}_{3}$ on the electroconductivity of $\mathrm{Au} @$ $\mathrm{Ag}$ nanoparticles was explored. Different amounts of $\mathrm{AgNO}_{3}(50,150,250,350$, and $450 \mu \mathrm{L})$ were added in the preparation of $\mathrm{Au} @ \mathrm{Ag}$ nanoparticles. Then, $8 \mu \mathrm{L}$ of $\mathrm{Au} @ \mathrm{Ag}$ nanoparticles with different $\mathrm{AgNO}_{3}$ additions were dropped on the surface of GE and left overnight at room temperature. The electrochemical signals were recorded using SWV. Results were presented in Figure 4A. The electrochemical signal first increased with the increasing amount of $\mathrm{AgNO}_{3}$. This could be ascribed to the excellent electron transfer performance of $\mathrm{Au} @$ $\mathrm{Ag}$ nanoparticles. But when the amount of $\mathrm{AgNO}_{3}$ exceeded $350 \mu \mathrm{L}$, the electrochemical signal gradually decreased, probably because too much $\mathrm{AgNO}_{3}$ increased the thickness of the shell of the $\mathrm{Au} @ \mathrm{Ag}$ core-shell structure, which may further affect the conductivity of $\mathrm{Au} @$ $\mathrm{Ag}$ nanoparticles. Hence, $350 \mu \mathrm{L}$ was selected as the optimal amount of $\mathrm{AgNO}_{3}$.

The incubation time of $\mathrm{AFM}_{1}$ with Apts could also affect the performance of the electrochemical aptasensor. The cDNA2-Au@Ag/Apt-Au@Ag/cDNA1/GE was incubated with $20 \mu \mathrm{L}$ of $\mathrm{AFM}_{1}\left(100 \mathrm{ng} \mathrm{mL}{ }^{-1}\right)$ for different times $(15,25,35,45$, and $55 \mathrm{~min})$ at room temperature and the electrochemical signals were measured using SWV. As shown in Figure 4B, the electrochemical signal was enhanced with increasing
A

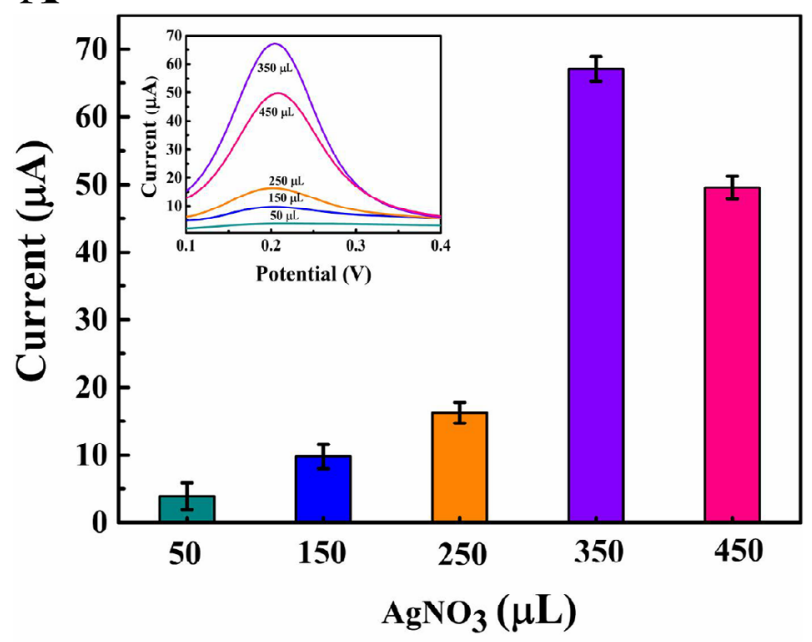

B

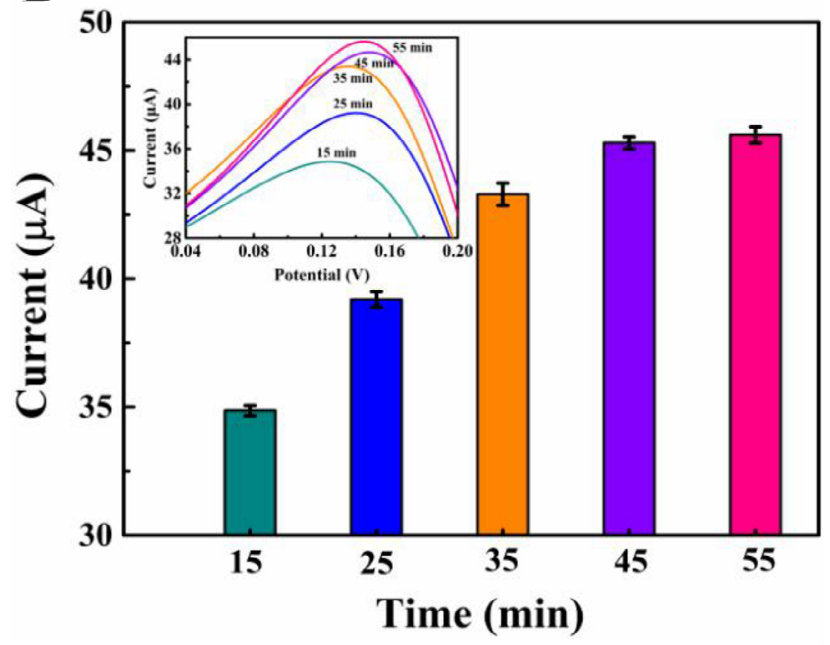

C

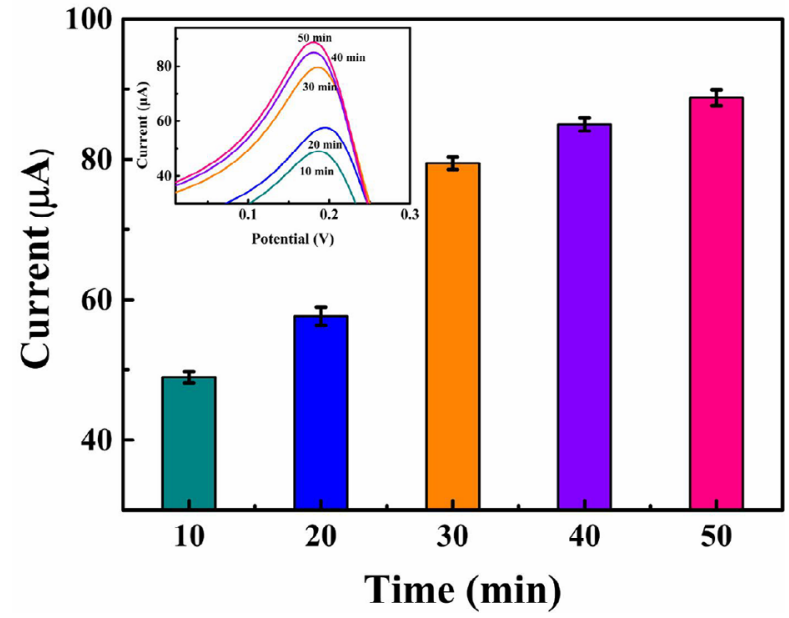

Figure 4. Optimization of the experimental conditions of (A) amount of $\mathrm{AgNO}_{3}$ added, (B) incubation time of $\mathrm{AFM}_{1}$ with aptamers (Apt), and (C) incubation time of methylene blue (MB). The data depict the average results of 3 experiments. 
Table 1. Comparison of the analytical performance with other reported methods for aflatoxin $\mathrm{M}_{1}$ detection

\begin{tabular}{lccl}
\hline Detection method & $\begin{array}{c}\text { Linear range, } \\
\text { ng mL }\end{array}$ & $\begin{array}{c}\text { Detection limit } \\
(\text { LOD }), \mathrm{ng} \mathrm{mL}^{-1}\end{array}$ & Reference \\
\hline LC-MS & $0.1-20$ & 0.05 & Fan et al., 2015 \\
ELISA & $2.5-80$ & 1 & Rosi et al., 2007 \\
Electrochemiluminescence aptasensor & $10-200$ & 0.05 & Khoshfetrat et al., 2018 \\
Optical aptasensor & $0.3-75$ & 0.03 & Jalalian et al., 2021 \\
Electrochemical aptasensor & $0.006-0.06$ & 0.00198 & Nguyen et al., 2013 \\
Electrochemical aptasensor & $0.01-80$ & 0.002 & Jahangiri-Dehaghani et al., 2020 \\
Electrochemical aptasensor & $0.05-200$ & 0.02 & This work \\
\hline
\end{tabular}

incubation time, and then almost kept stable after 45 min. This indicated that the combination between $\mathrm{AFM}_{1}$ and its Apts was completed, and the Apt-AFM complex formed on the surface of the electrode might have reached saturation. Thus, 45 min was selected as the optimum incubation time.

In addition, the effect of incubation time of $\mathrm{MB}$ on the aptasensor was also investigated. The $\mathrm{AFM}_{1} /$ cDNA2-Au@Ag/Apt-Au@Ag/cDNA1/GE was incubated with $20 \mu \mathrm{L}$ of $\mathrm{MB}(4 \mathrm{mM})$ for different times $(10,20,30,40$, and $50 \mathrm{~min})$ at room temperature. The SWV was used to monitor the signal of each electrode. From Figure 4C, it can be seen that the electrochemical signal gradually increased with an increase in the incubation time from 10 to $50 \mathrm{~min}$. When the incubation time was greater than $40 \mathrm{~min}$, the increasing signal was not significant. The reason could be explained by the enough MB adsorbed in the double stand DNA. Therefore, $40 \mathrm{~min}$ of $\mathrm{MB}$ incubation time was used in the following experimental study.

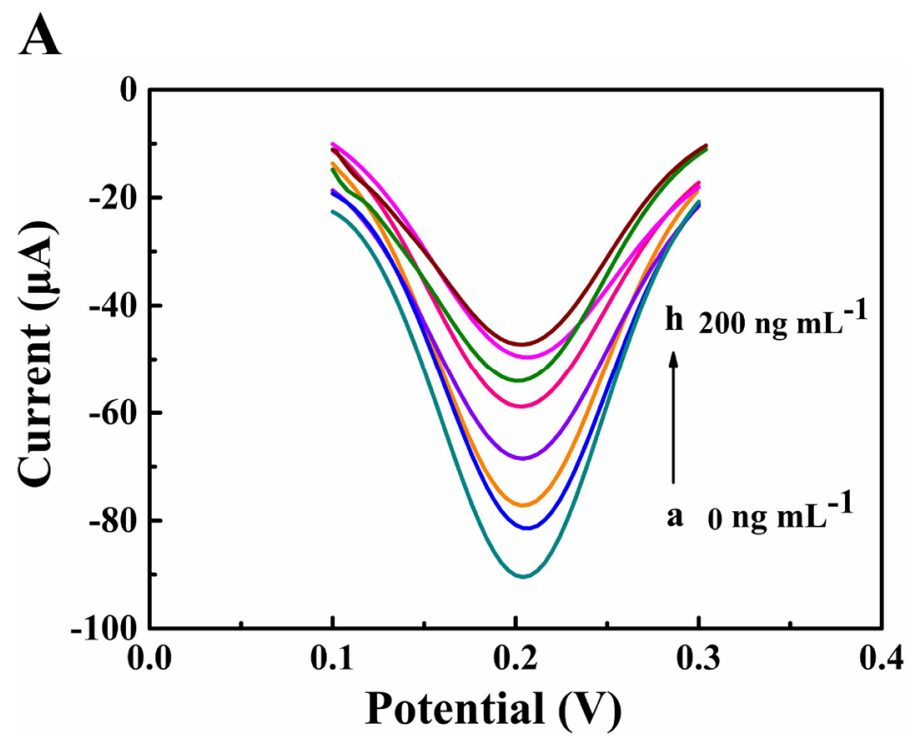

\section{Analytical Performance of the Fabricated Electrochemical Aptasensor}

Under the optimal experimental conditions, the DPV responses of the aptasensor at different concentrations of $\mathrm{AFM}_{1}\left(0.05,0.1,1,10,50,100\right.$, and $\left.200 \mathrm{ng} \mathrm{mL}^{-1}\right)$ were detected. As shown in Figure 5A, the electrochemical signal gradually decreased with increased $\mathrm{AFM}_{1}$ concentrations. Figure 5B shows a linear relationship between the variation value of the electrochemical signal relative to blank $(\Delta I)$ and the logarithm of $\mathrm{AFM}_{1}$ concentrations $\left(\log c_{\mathrm{AFM} 1}\right)$ from $0.05 \mathrm{ng} \mathrm{mL}^{-1}$ to 200 $\mathrm{ng} \mathrm{mL}^{-1}$. The linear regression equation obtained was $\Delta I(\mu \mathrm{A})=9.2441 \log c+21.8880$ with a correlation coefficient of 0.9973 , and the detection limit was estimated to be $0.02 \mathrm{ng} \mathrm{mL}^{-1}$ using the equation LOD $=3 \mathrm{~s} / \mathrm{n}$ (Skoog et al., 1998), in which $\mathrm{s}$ is standard deviation for the blank solution and $\mathrm{n}$ is the slope of the calibration curve (9.2441). Compared with other previously reported methods of $\mathrm{AFM}_{1}$ detection (Table

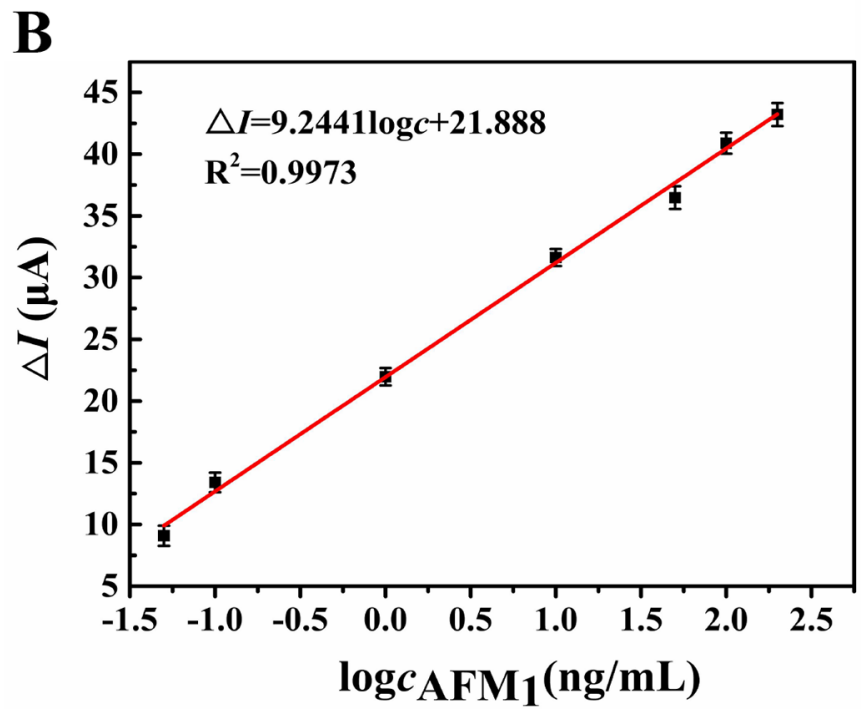

Figure 5. (A) Differential pulse stripping voltammetry (DPV) response of aflatoxin $\mathrm{M}_{1}\left(\mathrm{AFM}_{1}\right)$ at different concentrations (from a to h): $0,0.05,0.1,1,10,50,100$, and $200 \mathrm{ng} \mathrm{mL}{ }^{-1}$. (B) Linear relationship between the current signal change $(\Delta I)$ and the logarithmic value of the $\mathrm{AFM}_{1}$ concentration. Error bars represent the SD of the triplicates. 
1; Rosi et al., 2007; Nguyen et al., 2013; Fan et al., 2015; Khoshfetrat et al., 2018; Jahangiri-Dehaghani et al., 2020; Jalalian et al., 2021), the electrochemical aptasensor based on $\mathrm{Au} @ \mathrm{Ag}$ nanomaterials and redox probe MB demonstrates a wider linear range (4 orders of magnitude). Its performance was superior to some detection methods, particularly LC-MS and ELISA. The sample pretreatment of the aptasensor was not only simple, but also linear range and detection limit, perfectly satisfying the current detection requirement. This could be attributed to the following factors: First, the excellent electrical conductivity, high surface area and good biocompatibility were beneficial for charge transport and DNA immobilization of DNA, thus increasing the sensitivity of aptasensor. Moreover, using aptamers as the recognition element avoided the shortcomings of antibodies, such as poor stability and complicated preparation procedures, therefore, the sensitivity and selectivity of detection could be improved. In addition, MB was introduced into the sensing system and used as signal amplification element, which further improved the detection sensitivity. However, the approaches reported by Nguyen et al. (2013) and Jahangiri-Dehaghani et al. (2020) have higher sensitivity than our method. The reason could be explained by the fact that these approaches use nanomaterials with better conductivity, such as $\mathrm{Fe}_{3} \mathrm{O}_{4}$ incorporated polyaniline $\left(\mathrm{Fe}_{3} \mathrm{O}_{4} / \mathrm{PANi}\right)$ film and platinum nanoparticles loaded on Fe-based metal-organic frameworks [PtNP/ MIL-101(Fe)]. Thus, utilizing some novel nanomaterials with good conductivity was very meaningful to further improve the sensitivity of detection in further study.

\section{Reproducibility, Stability, and Selectivity of the Fabricated Electrochemical Aptasensor}

The reproducibility of aptasensor is another key factor to consider. To estimate the reproducibility, 5 electrodes prepared under the same conditions and steps were used to detect $\mathrm{AFM}_{1}$ of $100 \mathrm{ng} \mathrm{mL} \mathrm{m}^{-1}$. As shown in Figure 6A, these electrodes exhibited the closely current response, and their relative standard deviation is $6.35 \%$. The result demonstrated that this aptasensor has good reproducibility. Besides, the stability of the aptasensor was evaluated by long-term storage. After being stored for days at $4^{\circ} \mathrm{C}$, the electrochemical signal could remain at $92.9 \%$ of its initial signal (Figure $6 \mathrm{~B}$ ), indicating the aptasensor possessed desirable stability.

The selectivity of the aptasensor is an important factor affecting the analysis performance of the aptasensor. To estimate the selectivity of the method, the interfering substances, including $\mathrm{AFB}_{1}, \mathrm{AFB}_{2}$, $\mathrm{AFG}_{1}, \mathrm{AFG}_{2}$, aflatoxin $\mathrm{M}_{2}$, OTA, $\mathrm{FB}_{1}$, and mixtures $\left(\mathrm{OTA}+\mathrm{AFB}_{1}+\mathrm{FB}_{1}+\mathrm{AFM}_{1}\right)$, were also detected under

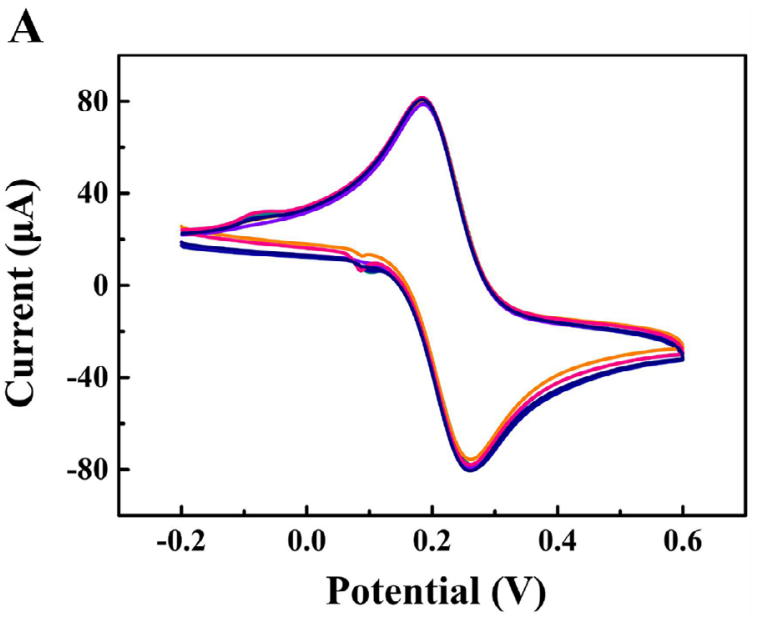

B

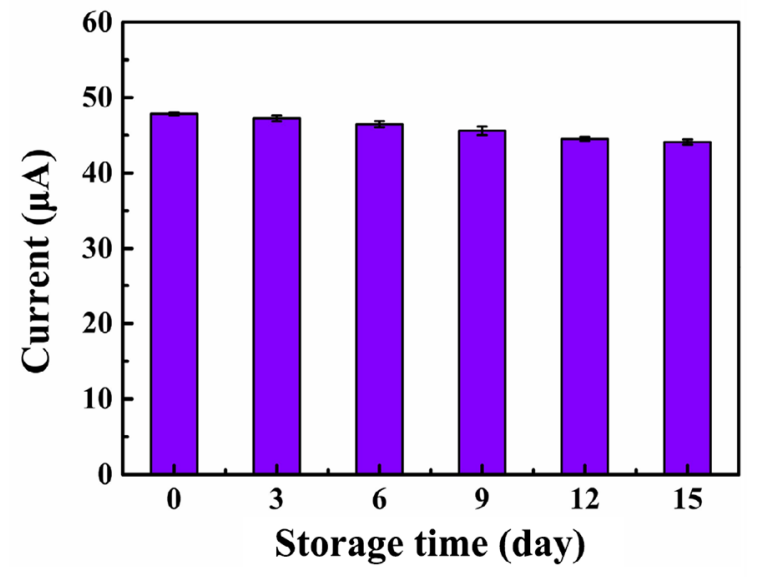

C

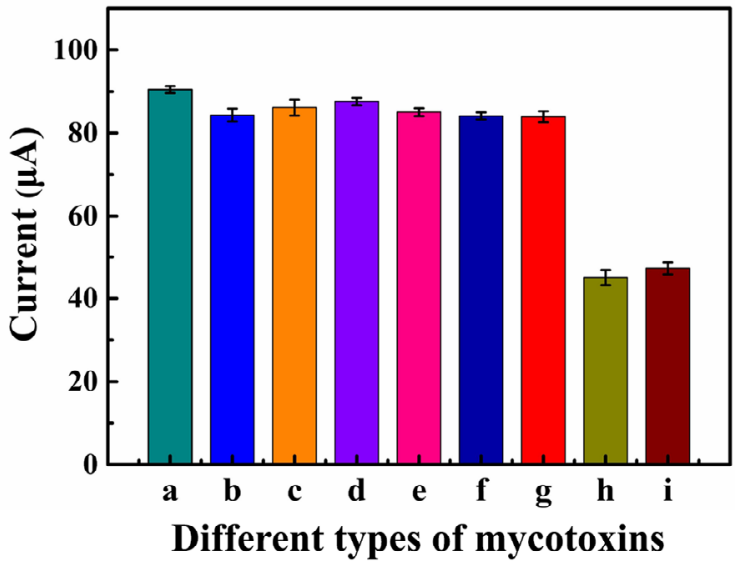

Figure 6. Evaluation of (A) reproducibility of the aptasensor [the different curves are representative of results obtained from 5 electrodes prepared under the same conditions and steps for the detection of 10 ng $\mathrm{mL}^{-1}$ aflatoxin M1 $\left(\mathrm{AFM}_{1}\right)$; (B) the stability of the aptasensor (concentration of $\mathrm{AFM}_{1}$ was $100 \mathrm{ng} \mathrm{mL} \mathrm{H}^{-1}$ ); and (C) the specificity of the aptasensor toward different interferences: (a) blank, (b) aflatoxin (AF) $\mathrm{B}_{1}$, (c) ochratoxin $\mathrm{A}(\mathrm{OTA})$, (d) fumonisin $\mathrm{B}_{1}\left(\mathrm{FB}_{1}\right)$, (e) $\mathrm{AFG}_{1}$, (f) $\mathrm{AFG}_{2}$, (g) $\mathrm{AFM}_{2}$, (h) OTA+AFB $+\mathrm{FB}_{1}+\mathrm{AFM} 1$ (OTA:AFB $1: \mathrm{FB}_{1}$ : $\mathrm{AFM}_{1}=1: 1: 1: 4$ ), and (i) $\mathrm{AFM}_{1}$. All mycotoxins were used at $100 \mathrm{ng}$ $\mathrm{mL}^{-1}$. 
Table 2. The detection results of aflatoxin $\mathrm{M}_{1}\left(\mathrm{AFM}_{1}\right)$ in the spiked pasteurized sheep milk samples with the electrochemical aptasensor $(\mathrm{n}=3)$

\begin{tabular}{lcccc}
\hline & \multicolumn{2}{c}{ AFM1 $\left(\mathrm{ng} \mathrm{mL}^{-1}\right)$} & & \\
\cline { 2 - 3 } Sample & Added & Detected & $\begin{array}{c}\text { Recovery, } \\
\%\end{array}$ & $\begin{array}{c}\text { Relative } \\
\text { SD, \% }\end{array}$ \\
\cline { 2 - 3 } Pasteurized goat milk & 150.00 & 143.72 & 95.81 & 7.87 \\
& 100.00 & 93.66 & 93.66 & 5.05 \\
& 10.00 & 9.21 & 92.12 & 5.24 \\
Pasteurized sheep milk & 1.00 & 0.94 & 94.00 & 4.98 \\
& 0.1 & 0.089 & 89.00 & 5.17 \\
& 150.00 & 156.07 & 104.05 & 5.16 \\
Pasteurized cow milk & 100.00 & 98.43 & 98.43 & 4.88 \\
& 10.00 & 9.11 & 91.10 & 7.02 \\
& 1.00 & 1.03 & 103.00 & 6.07 \\
& 0.1 & 0.095 & 95.00 & 4.65 \\
& 150.00 & 142.04 & 94.69 & 5.02 \\
& 100.00 & 95.75 & 95.75 & 5.77 \\
& 10.00 & 9.38 & 93.80 & 6.10 \\
& 1.00 & 0.94 & 94.00 & 4.32 \\
& 0.1 & 0.092 & 92.00 & 5.89 \\
\hline
\end{tabular}

the same condition. All concentrations of interfering toxins and $\mathrm{AFM}_{1}$ were $100 \mathrm{ng} \mathrm{mL} \mathrm{m}^{-1}$. As shown in Figure 6C, compared with the blank groups, a significantly weakened electrochemical signal was observed in the presence of $\mathrm{AFM}_{1}$, whereas there were no obvious changes in the electrochemical signal in the presence of other toxins. This could be explained by the high specific recognition ability of Apts toward $\mathrm{AFM}_{1}$, which also suggested that the electrochemical aptasensor possesses excellent selectivity for its target toxins.

\section{Testing of $\mathrm{AFM}_{1}$ in Milk}

To evaluate the potential application of the assay in real samples, the aptasensor was tested in cow, goat and sheep milk samples spiked with various concen-

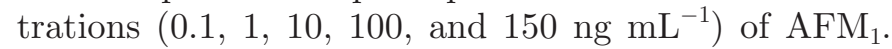
The detection results for $\mathrm{AFM}_{1}$ were demonstrated in Table 2. The recoveries were in the range of 89.00 to $104.05 \%$, and the relative standard deviations were 4.32 to $7.87 \%$. These results proved that the aptasensor has been successfully applied for $\mathrm{AFM}_{1}$ detection in milk samples.

\section{CONCLUSIONS}

In this study, we successfully demonstrated a novel electrochemical aptasensor based on layer-by-layer assembly of DNA-Au@Ag conjugates for $\mathrm{AFM}_{1}$ detection. The detection limit was as low as $0.02 \mathrm{ng} \mathrm{mL}^{-1}$, meeting the real-time and rapid detection requirements of government and the food industry. Furthermore, the construction process of the electrochemical aptasensor was straightforward, and the detection time was
85 min. In addition, the specific recognition of Apt toward $\mathrm{AFM}_{1}$ ensures this aptasensor possesses good repeatability and desirable stability and selectivity. Importantly, this electrochemical aptasensor has been successfully used to detect the $\mathrm{AFM}_{1}$ in cow, goat, and sheep milk samples with satisfactory results. This aptasensor offers a new method for the rapid and accurate detection of $\mathrm{AFM}_{1}$ in milk samples, and provides a promising electrochemical platform for determining contamination with other mycotoxins such as OTA, zearalenone, and $\mathrm{AFB}_{1}$.

\section{ACKNOWLEDGMENTS}

We appreciate the Key Industry Innovation Chain Project of Key R \& D Program in Shaanxi Province (2019ZDLNY06-06), the Science and Technology Program of Xi'an City (No. 20NYYF0014 and 20NYYF0018), the Fundamental Research Funds for the Central Universities (GK202003084), and the Project of Cooperating to Build Jinchang Meat Sheep Experimental Demonstration Base A289021806 (K3320219064). The authors have not stated any conflicts of interest.

\section{REFERENCES}

Amouzadeh Tabrizi, M., M. Shamsipur, R. Saber, S. Sarkar, and N. Sherkatkhameneh. 2017. Flow injection amperometric sandwichtype electrochemical aptasensor for the determination of adenocarcinoma gastric cancer cell using aptamer-Au@Ag nanoparticles as labeled aptamer. Electrochim. Acta 246:1147-1154. https://doi .org/10.1016/j.electacta.2017.06.115.

Bi, X., L. Li, X. Liu, L. Luo, Z. Cheng, J. Sun, Z. Cai, J. Liu, and T. You. 2021. Inner filter effect-modulated ratiometric fluorescence aptasensor based on competition strategy for zearalenone detec- 
tion in cereal crops: Using mitoxantrone as quencher of CdTe QDs@SiO ${ }_{2}$. Food Chem. 349:129171. https://doi.org/10.1016/j .foodchem.2021.129171.

Cavaliere, C., P. Foglia, C. Guarino, M. Nazzari, R. Samperi, and A. Laganà. 2007. Determination of aflatoxins in olive oil by liquid chromatography-tandem mass spectrometry. Anal. Chim. Acta 596:141-148. https://doi.org/10.1016/j.aca.2007.05.055.

Chen, W., C. Yan, L. Cheng, L. Yao, F. Xue, and J. Xu. 2018. An ultrasensitive signal-on electrochemical aptasensor for ochratoxin A determination based on DNA controlled layer-by-layer assembly of dual gold nanoparticle conjugates. Biosens. Bioelectron. 117:845851. https://doi.org/10.1016/j.bios.2018.07.012.

Ellington, A. D., and J. W. Szostak. 1990. In vitro selection of RNA molecules that bind specific ligands. Nature 346:818-822. https:// doi.org/10.1038/346818a0.

European Commission. 2010. Commission regulation (EU) No 105/2010 of 5 February 2010 amending regulation (EC) No 1881/2006 setting maximum levels for certain contaminants in foodstuffs as regards ochratoxin A. Off. J. Eur. Union 35:7-8.

Fan, S., Q. Li, L. Sun, Y. Du, J. Xia, and Y. Zhang. 2015. Simultaneous determination of aflatoxin $B_{1}$ and $M_{1}$ in milk, fresh milk and milk powder by LC-MS/MS utilising online turbulent flow chromatography. Food Addit. Contam. Part A Chem. Anal. Control Expo. Risk Assess. 32:1175-1184. https://doi.org/10.1080/ 19440049.2015 .1048311$.

Fang, B., S. Xu, Y. Huang, F. Su, Z. Huang, H. Fang, J. Peng, Y. Xiong, and W. Lai. 2020. Gold nanorods etching-based plasmonic immunoassay for qualitative and quantitative detection of aflatoxin $\mathrm{M}_{1}$ in milk. Food Chem. 329:127160. https://doi.org/10.1016/j .foodchem.2020.127160.

Feng, Z., N. Gao, J. Liu, and H. Li. 2020. Boron-doped diamond electrochemical aptasensors for trace aflatoxin $\mathrm{B}_{1}$ detection. Anal. Chim. Acta 1122:70-75. https://doi.org/10.1016/j.aca.2020.04 .062 .

FDA (US Food and Drug Administration). 2015. Compliance Policy Guide (CPG) Sec. 527.400. Whole milk, lowfat milk, skim milk aflatoxin $\mathrm{M}_{1}$. https://www.fda.gov/regulatory-information/search -fda-guidance-documents/cpg-sec-527400-whole-milk-lowfat-milk -skim-milk-aflatoxin-m1.

Frens, G. 1973. Controlled nucleation for the regulation of the particle size in monodisperse gold suspensions. Nature 241:20-22.

Gratz, S. W., V. Currie, G. Duncan, and D. Jackson. 2020. Multimycotoxin exposure assessment in UK children using urinary biomarkers-a pilot survey. J. Agric. Food Chem. 68:351-357. https:// doi.org/10.1021/acs.jafc.9b03964.

Hamami, M., A. Mars, and N. Raouafi. 2021. Biosensor based on antifouling PEG/gold nanoparticles composite for sensitive detection of aflatoxin $\mathrm{M}_{1}$ in milk. Microchem. J. 165:106102. https://doi .org/10.1016/j.microc.2021.106102.

He, H., D. W. Sun, H. Pu, and L. Huang. 2020. Bridging $\mathrm{Fe}_{3} \mathrm{O}_{4} @ \mathrm{Au}$ nanoflowers and $\mathrm{Au} @ \mathrm{Ag}$ nanospheres with aptamer for ultrasensitive SERS detection of aflatoxin $\mathrm{B}_{1}$. Food Chem. 324:126832. https://doi.org/10.1016/j.foodchem.2020.126832.

Jahangiri-Dehaghani, F., H. R. Zare, and Z. Shekari. 2020. Measurement of aflatoxin $\mathrm{M}_{1}$ in powder and pasteurized milk samples by using a label-free electrochemical aptasensor based on platinum nanoparticles loaded on Fe-based metal-organic frameworks. Food Chem. 310:125820. https://doi.org/10.1016/j.foodchem.2019 .125820 .

Jalalian, S. H., P. Lavaee, M. Ramezani, N. M. Danesh, M. Alibolandi, K. Abnous, and S. M. Taghdisi. 2021. An optical aptasensor for aflatoxin $\mathrm{M}_{1}$ detection based on target-induced protection of gold nanoparticles against salt-induced aggregation and silica nanoparticles. Spectrochim. Acta A Mol. Biomol. Spectrosc. 246:119062. https://doi.org/10.1016/j.saa.2020.119062.

Jalalian, S. H., M. Ramezani, N. M. Danesh, M. Alibolandi, K. Abnous, and S. M. Taghdisi. 2018. A novel electrochemical aptasensor for detection of aflatoxin $\mathrm{M}_{1}$ based on target-induced immobilization of gold nanoparticles on the surface of electrode. Biosens. Bioelectron. 117:487-492. https://doi.org/10.1016/j.bios.2018.06.055.
Jiang, W., Z. Wang, G. Nölke, J. Zhang, L. Niu, and J. Shen. 2013. Simultaneous determination of aflatoxin $\mathrm{B}_{1}$ and aflatoxin $\mathrm{M}_{1}$ in food matrices by enzyme-linked immunosorbent assay. Food Anal. Methods 6:767-774. https://doi.org/10.1007/s12161-012-9484-5.

Jiang, Y., D. Sun, H. Pu, and Q. Wei. 2020. A simple and sensitive aptasensor based on SERS for trace analysis of kanamycin in milk. J. Food Meas. Charact. 14:3184-3193. https://doi.org/10.1007/ s11694-020-00553-7.

Khodadadi, M., A. Malekpour, and M. A. Mehrgardi. 2018. Aptamer functionalized magnetic nanoparticles for effective extraction of ultratrace amounts of aflatoxin $\mathrm{M}_{1}$ prior its determination by HPLC. J. Chromatogr. A 1564:85-93. https://doi.org/10.1016/j.chroma .2018.06.022.

Khoshfetrat, S. M., H. Bagheri, and M. A. Mehrgardi. 2018. Visual electrochemiluminescence biosensing of aflatoxin $\mathrm{M}_{1}$ based on luminol-functionalized, silver nanoparticle-decorated graphene oxide. Biosens. Bioelectron. 100:382-388. https://doi.org/10.1016/j .bios.2017.09.035.

Kotlarek, D., F. Curti, M. Vorobii, R. Corradini, M. Careri, W. Knoll, C. Rodriguez-Emmenegger, and J. Dostálek. 2020. Surface plasmon resonance-based aptasensor for direct monitoring of thrombin in a minimally processed human blood. Sens. Actuators B Chem. 320:128380. https://doi.org/10.1016/j.snb.2020.128380.

Mao, K., Z. Yang, J. Li, X. Zhou, X. Li, and J. Hu. 2017. A novel colorimetric biosensor based on non-aggregated $\mathrm{Au} @ \mathrm{Ag}$ core-shell nanoparticles for methamphetamine and cocaine detection. Talanta 175:338-346. https://doi.org/10.1016/j.talanta.2017.07.011.

Ministry of Agriculture of China. 2017. GB 2761-2017. Limit of fungal toxins in food. Ministry of Agriculture.

Nguyen, B. H., L. D. Tran, Q. P. Do, H. L. Nguyen, N. H. Tran, and P. X. Nguyen. 2013. Label-free detection of aflatoxin $\mathrm{M}_{1}$ with electrochemical $\mathrm{Fe}_{3} \mathrm{O}_{4}$ /polyaniline-based aptasensor. Mater. Sci. Eng. C Mater. Biol. Appl. 33:2229-2234. https://doi.org/10.1016/j.msec .2013.01.044.

Qiao, L., H. Wang, J. He, S. Yang, and A. Chen. 2021. Truncated affinity-improved aptamers for 173-estradiol determination by AuNPs-based colorimetric aptasensor. Food Chem. 340:128181. https://doi.org/10.1016/j.foodchem.2020.128181.

Rosi, P., A. Borsari, G. Lasi, S. Lodi, A. Galanti, A. Fava, S. Girotti, and E. Ferri. 2007. Aflatoxin $\mathrm{M}_{1}$ in milk: Reliability of the immunoenzymatic assay. Int. Dairy J. 17:429-435. https://doi.org/10 .1016/j.idairyj.2006.05.003.

Sereshti, H., F. Khodayari, and N. Nouri. 2019. Simultaneous determination of aflatoxins in bread by in-syringe dispersive micro-solid phase extraction using magnetic three-dimensional graphene followed by HPLC-FLD. Food Anal. Methods 12:2273-2281. https:/ /doi.org/10.1007/s12161-019-01582-9.

Sevim, S., G. G. Topal, M. M. Tengilimoglu-Metin, B. Sancak, and M. Kizil. 2019. Effects of inulin and lactic acid bacteria strains on aflatoxin $\mathrm{M}_{1}$ detoxification in yoghurt. Food Control 100:235-239. https://doi.org/10.1016/j.foodcont.2019.01.028.

Shi, Y., W. Li, X. Feng, L. Lin, P. Nie, J. Shi, X. Zou, and Y. He. 2021. Sensing of mercury ions in Porphyra by Copper @ Gold nanoclusters based ratiometric fluorescent aptasensor. Food Chem. 344:128694. https://doi.org/10.1016/j.foodchem.2020.128694.

Skoog, D., F. Holler, and T. Nieman. 1998. Principles of Instrumental Analysis. Saunders College Publishing.

Song, D., R. Yang, S. Fang, Y. Liu, F. Long, and A. Zhu. 2018. SERS based aptasensor for ochratoxin a by combining $\mathrm{Fe}_{3} \mathrm{O}_{4} @ \mathrm{Au}$ magnetic nanoparticles and Au-DTNB@Ag nanoprobes with multiple signal enhancement. Mikrochim. Acta 185:491. https://doi.org/10 $.1007 / \mathrm{s} 00604-018-3020-2$.

Tuerk, C., and S. Macdougal-Waugh. 1993. In vitro evolution of functional nucleic acids: High-affinity RNA ligands of the HIV1 proteins. Gene 137:33-39. https://doi.org/10.1016/0378 -1119(93)90248-2.

Xu, W., H. Yi, Y. Yuan, P. Jing, Y. Chai, R. Yuan, and G. S. Wilson. 2015. An electrochemical aptasensor for thrombin using synergetic catalysis of enzyme and porous Au@Pd core-shell nanostructures 
for signal amplification. Biosens. Bioelectron. 64:423-428. https:// doi.org/10.1016/j.bios.2014.08.091.

Wang, X., R. Niessner, D. Tang, and D. Knopp. 2016. Nanoparticle-based immunosensors and immunoassays for aflatoxins. Anal. Chim. Acta 912:10-23. https://doi.org/10.1016/j.aca.2016.01.048.

Yao, L., Y. Ye, J. Teng, F. Xue, D. Pan, B. Li, and W. Chen. 2017. In vitro isothermal nucleic acid amplification assisted surface-enhanced raman spectroscopic for ultrasensitive detection of vibrio parahaemolyticus. Anal. Chem. 89:9775-9780. https://doi.org/10 .1021/acs.analchem.7b01717.

Zhang, W., Y. Wang, M. Nan, Y. Li, J. Yun, Y. Wang, and Y. Bi. 2021. Novel colorimetric aptasensor based on unmodified gold nanoparticle and ssDNA for rapid and sensitive detection of T-2 toxin Food Chem. 348:129128. https://doi.org/10.1016/j.foodchem.2021 .129128 .

Zhao, S., T. Bu, K. He, F. Bai, M. Zhang, Y. Tian, X. Sun, X. Wang, H. Zhangsun, and L. Wang. 2021. A novel $\alpha-\mathrm{Fe}_{2} \mathrm{O}_{3}$ nanocubes- based multiplex immunochromatographic assay for simultaneous detection of deoxynivalenol and aflatoxin $\mathrm{B}_{1}$ in food samples. Food Control 123:107811. https://doi.org/10.1016/j.foodcont.2020 .107811 .

Zhao, Y., Y. Yang, Y. Sun, L. Cui, F. Zheng, J. Zhang, Q. Song, and C. Xu. 2018. Shell-encoded Au nanoparticles with tunable electroactivity for specific dual disease biomarkers detection. Biosens. Bioelectron. 99:193-200. https://doi.org/10.1016/j.bios.2017 .07 .061 .

Zhou, Y., S. Xiong, K. Zhang, L. Feng, X. Chen, Y. Wu, X. Huang, and Y. Xiong. 2019. Quantum bead-based fluorescence-linked immunosorbent assay for ultrasensitive detection of aflatoxin $M_{1}$ in pasteurized milk, yogurt, and milk powder. J. Dairy Sci. 102:39853993. https://doi.org/10.3168/jds.2018-16109. 